\title{
Da letargia ao realento: notas sobre o ensino de graduação em administração pública no Brasil no entremeio da crise do Estado e da redemocratização no país (1983-94)*
}

\author{
Fernando de Souza Coelho** \\ Antonio Roberto Bono Olenscki*** \\ Rafael Prado Celso****
}

SumÁrio: 1. Introdução; 2. Da letargia ao realento: o ensino de graduação em administração pública no Brasil (1983-94); 3. Considerações finais.

Summary: 1.Introduction; 2 . From lethargy to re-emergence: undergraduate education in public administration in Brazil (1983-94); 3. Final remarks.

Palavras-chave: história; ensino de graduação; administração pública; Brasil.

KEY WORDS: history; undergraduate education; public administration; Brazil.

Considerando o entremeio da crise do Estado e da redemocratização no Brasil, este artigo volta-se para uma descrição e análise dos fatos e circunstâncias que marcaram o ensino de graduação em administração pública no Brasil no período 1983-94, considerado pelos autores como um dos ciclos (ou estágios de construção) desta formação acadêmica. Metodologicamente, o artigo faz a revisão bibliográfica daquelas

\footnotetext{
* Artigo recebido em dez. 2010 e aceito em ago. 2011.

** Doutor e mestre em administração pública e governo pela Escola de Administração de Empresas de São Paulo da Fundação Getulio Vargas (Eaesp/FGV). Professor doutor da Escola de Artes, Ciências e Humanidades (EACH) da Universidade de São Paulo (USP). Endereço: Campus USP Leste, Av. Arlindo Bettio, 1000, prédio I-1, sala 303-C, Ermelino Matarazzo - CEP 03828-000, São Paulo, SP, Brasil. E-mail: fernandocoelho@usp.br.

*** Doutor e mestre em administração pública e governo pela Eaesp/FGV. Professor titular da Escola de Negócios da Universidade Anhembi Morumbi (UAM). Endereço: rua Itapiru, 739, ap. 43 — Saúde — CEP: 04143-010, São Paulo, SP, Brasil. E-mail: aolenscki@gvmail.br.

**** Tecnólogo em sistemas de informação pela FTT, graduando em gestão de políticas públicas pela EACH da USP e mestrando em engenharia da informação pela Universidade Federal do ABC (UFABC). Endereço: Campus USP Leste, av. Arlindo Bettio, 1000, prédio I-1, sala 303-C, Ermelino Matarazzo — CEP 03828-000, São Paulo, SP, Brasil. E-mail: rafael.celso@usp.br.
} 
obras que abordam direta e indiretamente o tema, incluindo a revisita de suas fontes; analisa as leis e pareceres existentes sobre o ensino de graduação em administração pública nesse intervalo de tempo, bem como utiliza-se de algumas entrevistas semiestruturadas com acadêmicos que vivenciaram tal período. No que se refere aos resultados, observa-se que o período 1983-94, diferentemente do 1ํo ciclo (1952-65) e do $2^{\circ}$ ciclo (1966-82), quando a formação acadêmica em administração pública tinha uma identidade - aderente à concepção (e ao projeto) de Estado e aos contornos (e à produção) do campo do saber da administração pública —, tendo na Ebap/FGV um case modelar, foi um estágio de construção problemático, refletindo a crise do Estado dos anos 1980 e, igualmente, a crise (ou descontinuidade) paradigmática do campo do saber em administração pública no Brasil em tal época.

From lethargy to re-emergence: notes of undergraduate education in brazilian public administration during the crisis of state and country redemocradization (1983-94)

Considering the meantime of Brazilian crisis of State and redemocratization, this article looks for a description and analysis of the facts and circumstances that marked the undergraduate education of Brazilian public administration during this period, considered by the authors as one of the cycles (or stages of construction) of academic education. Methodologically, this article makes a review of academic and non-academic works which deal directly and indirectly the PA themes, including revisiting the sources and analyzing the existing laws and opinions about the undergraduate education in public administration in a continuum of time between 1983-94, through a semi-structured interview with academics who have experienced such period. Regarding the results, this article observes that the period between 1983-94, unlike the first cycle (1952-65) and second cycle (1966-82), when the academic background in public administration had an identity — adherent to the conception (and project) of State and the contours (and production) in the public administration field of knowledge — having the Ebap/FGV a model case, was a problematic stage of construction, reflecting the crisis of State in the 80's years and also the paradigmatic crisis (or discontinuity) in public administration field of knowledge in Brazil during this time.

\section{Introdução}

Historicamente, o "marco zero" do ensino de administração pública (AP) no Brasil — em nível de graduação - ocorre em 1952, com a instalação do curso na Escola Brasileira de Administração Pública da Fundação Getulio Vargas (Ebap/FGV). Nos dez anos subsequentes à criação do curso de graduação da Ebap/FGV, surgiram, no país, cursos de AP na Faculdade de Ciências Econômicas da Universidade Federal de Minas Gerais (UFMG, 1952), na Facul- 
dade de Administração da Universidade Federal da Bahia (UFBA, 1959), na Escola Superior de Administração da Universidade Federal de Pernambuco (UFPE, 1959), na Escola de Administração do Estado do Ceará (1961), e no Instituto de Ciências Humanas da Universidade de Brasília (UnB, 1961). Incluindo estas, estima-se que, entre 1952 e 1965, 31 Instituições de Ensino Superior (IES) implantaram cursos de formação acadêmica (graduação e pós-graduação) e/ou de treinamento e desenvolvimento (T\&D) em administração pública. Destas, aproximadamente $75 \%$ ofereciam o bacharelado nesse campo do saber, isolado ou integrado com o de administração de empresas (AE) (Machado, 1966).

Sobre os antecedentes desta formação acadêmica no país, destacamse os estudos de Silva (1960) e Fischer (1984) que, referendados por Coelho (2006, 2008b) e Nicolini (2007), mostram que as referências em torno do ensino de graduação em AP no Brasil, que precedem seu estabelecimento nos anos 1950, se dividem em três períodos desde a apreciação das reformas educacionais no Império à concretização da Fundação Getulio Vargas (FGV) em 1944, que, por seu turno, culminou na concepção da Escola Brasileira de Administração Pública (Ebap), no ano de 1952 (Coelho, 2008b:3).

Em relação ao período após 1952, Tânia Fischer (1984), em sua tese de doutorado $O$ ensino de administração pública no Brasil, os ideais de desenvolvimento e as dimensões da racionalidade, demonstra que a política/estratégia de formação de administradores públicos no Brasil se pautou pela eficiência, racionalização e planificação (princípios) que, com a cooperação internacional, se internalizaram em centros de ensino, pesquisa e assistência técnica (meios), guiados para a modernização do Estado e o desenvolvimento nacional (fins). Contextualmente, a autora identifica três fases da capacitação de administradores públicos diante das etapas conjunturais do Estado brasileiro entre os anos 1930 e o limiar dos anos 1980. Desde então, tais fases se tornaram referência na literatura para o estudo do ensino de administração pública no país (Fischer, 1984:30).

No projeto de pesquisa do qual deriva este artigo, tomamos as "fases" de Fischer para examinar a trajetória da graduação em administração pública no Brasil como variável dependente das vicissitudes do Estado nacional e das conformações do campo do saber em administração pública no país, identificando três ciclos pelos quais os cursos de bacharelado em AP passaram entre 1952-94:

- 1o ciclo (1952-65) - diante de um pró-ciclo estatal e favorecido pela assistência técnica norte-americana, o ensino superior de administração pública 
irradiou-se no Brasil no período 1952-65. Nascido sob o signo da administração científica (aplicada ao setor público) na Ebap em 1952, o bacharelado em AP reproduziu-se em IESs pelo país, preponderantemente nas universidades federais, com a ascendência da administração para o desenvolvimento, na medida em que aos processos administrativos do governo agregavam-se as funções econômico-sociais do Estado. A vivacidade e fluidez de tal ensino, naturalmente, desenvolveram nos cursos uma identidade - coletiva - de formar quadros de pessoal para a burocracia estatal;

v 2o ciclo (1966-82) — no final dos anos 1960, o bacharelado em AP, em seu auge, reconhecido pelo MEC, divulgado entre os vestibulandos e regulamentado como profissão, ampliou suas vagas e ajustou seus currículos, diversificando-se com a administração para o desenvolvimento (planificação econômica, planejamento governamental), em voga na atividade do Estado e na agenda de pesquisa do campo do saber neste período. Sem embargo, em meados dos anos 1970, o enforcement do currículo mínimo de administração - com lógica de administração de empresas (AE), a diluição do ethos de administração pública com a sobreposição da gestão empresarial no "Estado-empresa" e o milagre econômico (e o consequente boom do ensino de $\mathrm{AE}$ ), retraíram o ensino de graduação em administração pública no país; cada vez mais, a administração no Brasil se tornava, então, sinônimo de administração de empresas;

- 3o ciclo (1983-94) — a retração do ensino de graduação em administração pública no Brasil nos anos 1970 converteu-se em letargia na década dos 1980, simbolizada pela descontinuidade do bacharelado da Ebap/FGV em 1982. Em um contexto de crise do Estado, subentendia-se uma perda da razão de ser e/ou desnecessidade de cursos de graduação em administração pública. Das experiências - tradicionais — dos anos 1960-70, remanescia o curso da Eaesp/FGV. É a partir da Constituição de 1988 que se retomaria — timidamente - o ensino de graduação em administração pública no país; continuado na Eaesp/FGV e criado na Unesp (1989) e EG/FJP (1994), tal ensino realentaria em meados dos anos 1990, numa conjuntura de reforma do Estado e ampliação do locus do setor público no país.

Do impulso dos anos 1950 à letargia do final dos anos 1970, a formação acadêmica em AP encetou sua trajetória no país. Grosso modo, tal ensino, moribundo vis-à-vis à crise do Estado nos anos 1980, revitalizou-se com a agenda de reforma do Estado após 1995. Assim, já se passou meio século de história, desde o pioneirismo da Ebap/FGV, que formou em 1954 os primeiros bacharéis em administração pública no país, até o (re)surgimento de cursos nesse campo 
do saber em instituições de ensino como Udesc (2004), USP (2005), Unicamp, UFMG, UnB, UFRGS e UFRN (2009), UFABC, Ufla, UFPB e UFRJ (2010).

É evidente que entre os ciclos - supramencionados - ocorreram rupturas, mudanças e adaptações nas ideias/valores, na organização pedagógico-curricular e nos vínculos com o setor público dessa formação acadêmica, caracterizando, temporalmente, estágios de construção, cujas descrições e análises constituem o objetivo do projeto de pesquisa que origina este artigo. Em artigos publicados nos eventos da Anpad, um dos autores apresentou o $1^{\circ}$ e o $2^{\circ}$ ciclos; neste artigo, os autores apresentam o $3^{\circ}$ (e último) ciclo, realizando um compêndio, ora descritivo, ora analítico, do ensino de graduação em AP no Brasil no período 1983-94, demarcado por sua letargia diante da crise do Estado (e do campo do saber) nos anos 1980 e por seu — relativo - realento na pós-redemocratização.

Metodologicamente, o artigo se constrói pela:

v revisão bibliográfica de obras que abordam direta e indiretamente o tema, incluindo a revisita de suas fontes de consulta;

- análise documental de leis e pareceres sobre o ensino de graduação em administração pública e projetos pedagógicos, prospectos e textos de discussão de instituições de ensino que ofereciam esse curso em tal época;

- realização de entrevistas semiestruturadas com acadêmicos (diretores de IESs e coordenadores; professores de cursos de AP) que vivenciaram tal período, sendo, portanto, copartícipes desta história.

Ressalta-se que a importância de trabalhos de tal natureza reside na contribuição para a construção de uma memória do campo do saber em administração pública no Brasil, em geral, e do seu ensino (e pesquisa), em particular. Ademais, o artigo se justifica pela escassez de estudos/abordagens historiográficas na produção acadêmica nacional em administração pública, visto que, segundo Pacheco (2003:69), "os autores privilegiam temas da atualidade", vinculando - frequentemente - o front de pesquisa com a agenda de governo.

\section{Da letargia ao realento: o ensino de graduação em administração pública no Brasil (1983-94)}

No início dos anos 1980, a retração do ensino de graduação em administração pública no Brasil - iniciada em meados dos anos 1970 - converteu-se em letargia, simbolizada pela descontinuidade do curso de bacharelado em AP da Ebap/FGV. O enforcement do currículo mínimo de administração - com lógica de $\mathrm{AE}-\mathrm{e}$ as desvantagens do mercado de trabalho no setor público 
vis-à-vis às oportunidades na iniciativa privada juntar-se-iam à crise do Estado bem como à transição - com suas incertezas — do paradigma de administração pública no país, deslocando (e reduzindo) a formação acadêmica neste campo do saber para o nível de pós-graduação. Das experiências - tradicionais - de ensino de graduação em AP no país, nos anos 1960/70, remanesciam o curso da Eaesp/FGV e, regionalmente, o curso da UnB.

Agonizante nos anos 1980, da Constituição de 1988 às discussões/tentativas de reforma do Estado no início dos anos 1990 - com pauta (e projetos) sobre Estado mínimo, ajuste fiscal, descentralização e (re)democratização —, o bacharelado em administração pública realentaria, gradativamente, perante a retomada da profissionalização no serviço público, o aumento da governança (e das políticas públicas) no nível subnacional e a emergência do terceiro setor. A Eaesp, a Universidade Estadual Paulista (Unesp) e a Fundação João Pinheiro (FJP) conformariam a tríade do ensino de graduação em AP no Brasil nos anos 1990.

A seguir, em subseções, desvelaremos - minuciosamente - os fatos e as circunstâncias desse $3^{\circ}$ ciclo do ensino de graduação em administração pública no Brasil.

\subsection{A letargia do ensino de graduação em administração pública no país nos 1980 em um contexto de crise do Estado e de transição do paradigma do campo do saber}

\subsubsection{Preâmbulo}

No artigo "Formação do administrador público: alternativas em debate", publicado na Revista de Administração Pública (RAP) em 1981, Bianor Cavalcanti professor da Ebap/FGV —, discutindo a natureza dos programas de formação acadêmica e de treinamento e desenvolvimento (T\&D) em administração pública no Brasil e a adequação desta educação para a modernização administrativa do Estado, alegara que as IESs (e escolas de governo), quer por suas missões e objetivos - e os seus cursos (e treinamentos) - , quer por seus formatos e conteúdos, se incompatibilizavam com as necessidades manifestas e demandas potenciais de profissionalização dos executivos do setor público. Sobre o ensino de graduação em administração pública, Bianor Cavalcanti (1981:42) frisara:

Na academia, os cursos de graduação em administração pública, com duração de quatro anos, atraem, basicamente, os jovens egressos do curso secundário, em relação aos quais não é certo o ingresso no serviço público e, muito menos, a ascensão aos cargos de direção e assessoramento no alto escalão. Note-se ainda 
que tais cursos formam o técnico de administração pública, em geral orientado para [as áreas funcionais como] O\&M, RH, Orçamento e cujo papel é de natureza diversa daquele do administrador público. Este não seria necessariamente um especialista em qualquer das funções administrativas, principalmente quando viesse a ocupar cargos diretivos [envolvendo formulação de estratégias e tomada de decisões]. Evidentemente, muitos conhecimentos, incluindo aqueles sobre organização e/ou gerência, bem como o domínio de suas técnicas, objetos de estudo do bacharelado em administração pública, são pertinentes ao interesse de quaisquer administradores públicos. Estes, porém, em sua maioria já graduados em outras profissões, não consideram compensador, por motivos diversos, o investimento demorado em outro curso de graduação, nem socialmente desejável esse investimento de quatro anos de estudo (grifo nosso).

Constatações como esta - de não atingir ou cumprir, como nos anos 1950-60, o papel de escola de governo — , aliadas ao déficit econômico-financeiro do curso, levaram à interrupção do curso de graduação em AP na Ebap/FGV, concentrando-se esta IES, a partir de 1983, no ensino de pósgraduação. Segundo Armando Cunha - professor da escola e na ocasião vice-diretor de ensino:

havia dentro da Ebap uma forte corrente que achava que a missão da escola no plano da graduação estava cumprida. Havia alguma discordância, mas prevaleceu a ideia de que já existiam muitos cursos de graduação [em administração] no Brasil. [...] a presidência [da FGV] dizia que tínhamos que fazer aquilo que os outros não podiam fazer. [Além disso], a questão era não crescer e, para não expandir, tínhamos que abrir mão de alguma coisa. (entrevista realizada pelos autores).

A grade curricular ebapiana, em 1980, confirma as palavras (e análise) do entrevistado; o curso da Ebap, com as reformas (e adaptações) curriculares, desde os anos 1970, era, na verdade, um bacharelado em administração, em vez de uma graduação — de fato — em administração pública. E, portanto, o argumento de que já havia muitos cursos de administração no país era plausível.

Na Eaesp/FGV, por sua vez, pelas palavras de Fernando Carmona diretor da escola no período 1979-83:

a presidência da FGV percebeu que não era fácil fechar o curso de administração [o qual era o coração da escola]. O Conselho Federal de Educação (CFE) já tinha se manifestado [contra o fechamento], o Conselho de Administração foi mobilizado, e aí a FGV acabou, em um documento escrito da Direção, impondo certos ajustes [para a continuidade do curso]. (entrevista realizada pelos autores). 
Extinção do curso noturno, aumento do valor das mensalidades - no caso do curso de AE, visto que o curso de AP era gratuito (subsidiado pelo governo do estado de São Paulo) —, diminuição do número de disciplinas optativas, redução do quadro de professores extracarreira com o incremento da carga horária dos professores de carreira, além da criação de um fundo pela Febraban cujos rendimentos eram transferidos para a operação da escola, constituíram, alternativamente, um plano que reduziu as despesas e elevou as receitas da Eaesp, mitigando as razões financeiras apontadas pela mantenedora para extinguir o curso de graduação nesta escola. Resultado: em março de 1981, o CFE concordou com a suspensão do vestibular e o fim do bacharelado na Ebap, a pedido da FGV, por escassez de recursos, mantendo-o na Eaesp.

Salienta-se que na Eaesp o convênio com o governo estadual foi fundamental para a - relativa - autonomia financeira da escola diante da FGV, subsidiando, parcialmente, o bacharelado em administração nessa IES, no caso, a opção em administração pública. Mantido em São Paulo, o ensino de graduação em AP na Eaesp, apesar de tradicional no país, não alcançou, imediatamente, a magnitude e a liderança tal qual o bacharelado da Ebap lograra; este curso, historicamente, era o benchmark do ensino superior de administração pública, em nível de graduação, no Brasil e na América Latina. Enquanto sua instalação em 1952 impulsionou o ensino de graduação em administração pública nacional, sua interrupção em 1983 esvaziou — grosso modo — o significado desse ensino; embora, na ocasião, o curso da Ebap fosse uma graduação tout court (com ênfases em AP e AE), sua descontinuidade na pioneira (e principal) escola de administração pública do país significava uma perda da razão de ser e/ou desnecessidade do bacharelado em AP. Para detalhes sobre o curso de graduação em AP da Ebap/FGV, veja o quadro 1.

Se o estudo de AP ofuscava-se, inversamente, a opção por AE no ensino de graduação em administração inflava-se; os 31 cursos em 1967 - dos quais, aproximadamente, 2/3 eram de administração pública ou enfatizavam este campo do saber — , em 15 anos, de acordo com Fleury (1983), saltaram para 245 cursos, matriculando 146 mil alunos e formando 21 mil bacharéis/ano, basicamente, em administração de empresas. Na verdade, esse boom nos cursos de administração advém dos estímulos dos anos 1960-70: por um lado, a ampliação do mercado de trabalho empresarial e a explosão do fluxo de egressos do ensino de $2^{\circ}$ grau - em decorrência de reformas educacionais, entre as quais a implantação do ensino supletivo - aumentaram a demanda pelo ensino superior de administração; por outro lado, a Reforma Universitária de 1968 facilitou, na proporção do aumento da demanda, o incremento da oferta dos cursos de graduação nesta área do conhecimento. Como defende Carlos Benedito Martins (1986:12), em sua tese de doutorado, era o rencontre d'une demande social et d'une oppotunité politique no regime militar. 


\section{Quadro 1 \\ A Ebap e o ensino de graduação em AP no Brasil (1952-83)}

O percurso do bacharelado da Ebap/FGV e a trajetória da graduação em administração pública no Brasil, normalmente, se confundem pela importância daquela escola (e de seu curso) para este ensino superior no país - desde o limiar dos anos 1950 até meados dos anos 1980.

É patente que o curso da Ebap, como "ator principal" da graduação em administração pública nacional no período 1952-83, refletiu - historicamente - os ciclos deste ensino superior, sendo uma evidência para tal estudo. No que se refere ao 10 ciclo constatou-se que a Ebap foi a pioneira e sempre a mais prestigiosa entre as quase duas dezenas de IESs que encetaram o bacharelado em administração pública no país entre 1952-65, tornando-se benchmark pátrio (e internacional). Neste período, a escola forjou o currículo da graduação em administração pública; formou docentes neste campo do saber; ensejou a tradução de obras e a publicação de manuais, monografias e artigos para constituir uma literatura adequada (e especializada) à formação acadêmica em AP; incorporou disciplinas de conteúdo e aplicações novas no contexto nacional; logrou recrutar - nacionalmente - um alunado disposto a investir numa carreira que ainda encontrava-se em vias de definição; e pugnou pelo reconhecimento do ensino de administração e pela regulamentação da profissão de administrador no Brasil.

Adiante, no 2o ciclo (1966-82), ainda nos anos 1960, de acordo com Bianor Cavalcanti "a Ebap era o resultado de duas matrizes: a University of Southern California e o Dasp [Departamento Administrativo do Serviço Público]; [...] essa ponte entre a public management norte-americana e a racionalidade administrativa daspiana [aplicada ao setor público], conferiram à escola uma identidade"* Além disso, segundo Paulo Motta, "as pesquisas - publicadas na RAP - e a extensão (assessoria, consultoria e T\&D no governo) contribuíam para a atualidade/pertinência do ensino"* Esse auge do bacharelado da Ebap era, também, o auge do ensino de administração pública no Brasil.

No entanto, após 1970, no encalço da legislação dos cursos de administração e da valorização da gestão empresarial no país, a grade curricular da Ebap - tipicamente de AP no antanho da escola - foi, gradativamente, interposta por disciplinas de AE. Nas palavras de Armando Cunha, "o interesse [dos alunos] pelo setor público tornou-se, cada vez mais, discreto. Em meados dos anos 1970, a Ebap era uma escola de administração pública que formava, preponderantemente, administradores de empresas"* De fato, essa realidade, além da Ebap, abrangia todas e quaisquer IESs com curso de graduação em administração pública no Brasil; tanto a junção do ensino superior de AP e AE pelo currículo mínimo - aderente ao "Estado-empresa" - quanto o milagre econômico - demandante de administradores de empresas - retraíram o ensino de administração pública.

Em 1983, por alegações financeiras (e de reposicionamento da escola para a pós-graduação), a descontinuidade do bacharelado da Ebap abre o 3o ciclo (1983-94) do ensino de graduação em administração pública no Brasil, no qual a retração dos anos 1970 converteu-se em letargia na década seguinte. À época, tanto a crise do Estado (e do paradigma de administração pública) despropositava tal ensino no país, como a aproximação da AP com a AE - em grade curricular - descaracterizava seus cursos (e conteúdos).

Novamente, as histórias de um e de outro convergiam: assim como a instalação da Ebap em 1952 impulsionou o ensino de graduação em administração pública no Brasil, a interrupção de seu bacharelado em 1983 simbolizou - nacionalmente - o esvaziamento desse ensino nos anos 1980.

Fonte: elaboração dos autores, baseada em Coelho (2006).

* Trechos de entrevistas realizadas pelo autor. 
Tal expansão do ensino superior de administração — na acepção de $\mathrm{AE}$ - no país, em geral, ocorreu nas instituições de ensino superior privadas, sobretudo, nas faculdades isoladas. Por conseguinte, em 1983, os cursos de graduação em administração dessas IESs abrigavam $63 \%$ dos graduandos nesta área do conhecimento, tornando a formação acadêmica em administração assimétrica; ao passo que as universidades (e escolas) públicas e confessionais, em função da qualificação de seu corpo docente, de suas práticas de ensino e pesquisa, da imagem social que produziam de si mesmas e da ligação com o mercado de trabalho, formavam uma elite administrativa, as faculdades isoladas, concentradas na oferta de um ensino de baixo custo com menores exigências acadêmicas e em período noturno, instruíam alunos-trabalhadores para as áreas de baixa gerência das empresas. A partir desta segmentação, tal abundância de bacharelados em administração seria questionada (e criticada) em seu aspecto qualitativo. O quadro 2 elenca os autores que debatiam a qualidade do ensino de graduação em AE no país nos anos 1970-80, resumindo os argumentos de suas obras e/ou seus escritos.

\section{Quadro 2 \\ Críticas ao ensino de graduação em administração no Brasil nos anos 1970-80}

\begin{tabular}{|l|l|}
\hline Ano & Autor e argumento \\
\hline 1974 & $\begin{array}{l}\text { Autor: Moura Castro. Argumento: a profissionalização do administrador acarretou o surgimento } \\
\text { (e desenvolvimento) de cursos amadores, com falhas na formação teórica e formação prática } \\
\text { de arremedo. Nesses cursos, as deficiências dos alunos e a inadequaça dos professores (e da } \\
\text { estrutura acadêmica) tornam o ensino de administração informativo e as instituiçães de ensino } \\
\text { que o oferecem meramente diplomadoras. }\end{array}$ \\
\hline 1980 & $\begin{array}{l}\text { Autor: Covre. Argumento: os acordos MEC-Usaid após 1964, em geral, e a reforma universitária } \\
\text { de 1968, em particular, conferiram ao sistema universitário nacional uma espécie de racionalidade } \\
\text { instrumental em termos de eficiência tecnoprofissional. Neste contexto, o ensino de administração } \\
\text { voltou-se - excessivamente - para os instrumentos/modelos aplicados a empresas; a } \\
\text { nomenclatura da profissão - técnico de administração - reforça (e valoriza) a tecnificação. Para a } \\
\text { autora, esse papel do curso de graduação em administração de empresas era tacanho/reducionista. }\end{array}$ \\
\hline 1983 & $\begin{array}{l}\text { Autor: Prestes Motta. Argumento: o ensino de administração fracionado/parcelado, em } \\
\text { consonância com a divisão do trabalho nas empresas (recursos humanos, produção, } \\
\text { mercadologia e finanças) é falho, pois atomiza a realidade e faz-se acrítico. O autor diz que a } \\
\text { vocação para o estudo das áreas funcionais no ensino de graduação de administração relegou } \\
\text { os estudos organizacionais de sociologia política e psicologia social. }\end{array}$ \\
\hline 1989 & $\begin{array}{l}\text { Autor: Martins. Argumento: os cursos de administração nas faculdades isoladas encontram } \\
\text { no princípio que os estruturam - vale dizer, a rentabilidade - o limite (e o obstáculo) } \\
\text { intransponível para aperfeiçoar suas práticas/estruturas acadêmicas, diferentemente das IESs } \\
\text { de ensino e pesquisa. Com isto, são conduzidos a ocuparem posições de segundo plano no } \\
\text { campo do ensino de graduação em administração no país, limitando-se, muitas vezes, de } \\
\text { maneira perversa, à concessão de uma frágil "cidadania profissional". }\end{array}$ \\
\hline
\end{tabular}

Fonte: elaboração dos autores. 
Nesse avolumado de cursos de graduação em administração no Brasil, a classe dos técnicos de administração se fortaleceu; em 1985 alterava-se a denominação da profissão para administrador — Lei no 7.321, de 13 de junho de 1985 —, 20 anos após sua regulamentação. Reivindicação antiga e questão - aparentemente - simples, a mudança envolveu debates, manifestações e campanhas desde meados dos 1970 até 1983, quando o Ministério do Trabalho consentiu tramitá-la e, posteriormente, referendá-la. Equidistante da dimensão quantitativa do bacharelado em $\mathrm{AE}$ e da profissiografia deste campo do saber, o ensino de graduação em AP, sem o referencial da Ebap/FGV e em um contexto de crise do Estado e de transição do paradigma de administração pública no país, subsistia restrita e adversamente; poucas IESs ofereciam a opção (ou ênfase) em administração pública em seus cursos de administração, destacando-se a Eaesp e a UnB. De fato, a diminuição do intervencionismo estatal, o esgotamento político-administrativo do Estado autoritário e a paralisação da reforma administrativa (e dos concursos públicos) cessaram a demanda por administradores públicos na década dos 1980.

\subsubsection{Crise do estado, crise do campo do saber, crise do ensino de graduação}

Na ocasião dos anos 1980, sendo o termo "público" sinônimo do vocábulo "estatal", isto é, administração pública era per se gestão estatal, o ambiente (e cenário) desorientador do Estado brasileiro, em geral, e do mercado de trabalho no setor público, em particular, despropositou o ensino de graduação em administração pública no país, tornando-o letárgico. Considerando o número de IESs que ministravam tal ensino e a oferta de vagas de seus cursos, estima-se que os formandos em AP correspondiam a 1\% dos egressos dos bacharelados em administração; aproximadamente, 200 bacharéis/ano. Além da Eaesp/FGV, nas universidades públicas, o curso de graduação em administração pública manteve-se distinto (e separado) do curso de administração de empresas em poucas IESs, entre as quais a UnB, a Uece e, parcialmente, a UFBA. No Brasil, via de regra, o ensino de AE absorvia o ensino de AP.

Contudo, a pós-graduação em AP cresceu na década dos 1980, tanto no nível de especialização como nos estudos de mestrado. Na Ebap/FGV, com a extinção do bacharelado, a escola expandiu o Curso Intensivo de Pós-Graduação em Administração Pública (Cipad), criado em 1978, replicando-o em Brasília, Porto Alegre, Salvador, Recife, Goiânia e Campo Grande. Destinado aos técnicos, assessores e gerentes públicos, independentemente da formação 
acadêmica, esse curso de especialização, apoiado (e financiado) pelo Ministério do Planejamento e por governos estaduais, figurou como um treinamento in the job tal qual uma escola de governo. Com duração de um ano - com oito disciplinas, totalizando 32 créditos — , seu interesse (e tamanho) é desvelado pelos seus 800 concluintes no período 1979-84, 2/3 do número de bacharéis que a Ebap formou em 30 anos (Costa, 1984; e entrevista realizada pelo autor com Paulo Motta). Na Eaesp, em 1985, a área de concentração de "administração e planejamento urbano" do Curso de Mestrado em Administração de Empresas tornou-se autônoma, originando o Curso de Mestrado em Administração Pública (CMAP) nesta escola; além desta área de concentração, introduziu-se a área de "economia e finanças públicas", incrementando tal programa. Entrementes, a formação acadêmica em AP no Brasil, apática na graduação, sustentou-se na pós-graduação.

Conquanto a pós-graduação lato sensu orientava-se para a área de public management no entremeio do Programa Nacional de Desburocratização e da agenda de desestatização, a pós-graduação stricto sensu movia-se para os estudos de políticas públicas em um momento tanto de retomada do estado de direito, com a (re)construção do espaço público, quanto de reconceituação de desenvolvimento - de crescimento econômico para transformação produtiva com equidade social. Citam-se os cursos de mestrado em administração pública da Ebap, UFBA e Eaesp.

O curso da Ebap, além da área de concentração de políticas públicas, desde 1983, oferecia um domínio conexo (minors) em políticas sociais (educação, saúde etc.). O curso da UFBA, em 1988, articulava o estudo das organizações públicas com o estudo da sociedade civil (e dos atores sociais) em nível local. A Eaesp, em 1989, criava em seu curso a área de concentração de políticas de governo para o estudo de políticas públicas (agenda, formulação, implementação e avaliação). Outrossim, os programas de pós-graduação em ciências sociais, como os da USP e do Iuperj, intensificariam em suas áreas de concentração em ciência política os estudos de governo (e de políticas públicas).

Nesse ínterim, o estudo do aparelho do Estado através de um focus da ciência administrativa (eficiência, modernização etc.) desviou-se para o estudo das relações Estado-sociedade com um focus da ciência política (legitimidade, poder etc.). Para Mezzomo Keinert (1998:41-42), essa transição do paradigma da administração pública brasileira nos anos 1980 — verificada na produção técnico-científica - era, realmente, uma "crise do conceito de público enquanto estatal e a emergência do conceito de público como interesse público" no campo do saber. 
O reordenamento político-administrativo do Estado após 1985 e o paradigma de administração pública que se delineava no país - sociocêntrico — alteravam, também, a lógica (e os critérios) de racionalidade das instituições/ empresas estatais. Sem o autoritarismo, o insulamento (tecno)burocrático se desfazia, reintegrando o processo político na gestão pública. Conciliar demandas sociais, conviver com as relações de poder entre governo e atores sociais, negociar (e legitimar) decisões e viabilizar a ação coletiva perfariam um "rol" de capacidade política tão importante para o administrador público quanto para a competência técnica. Destarte, a administração pública nacional, despida da política e identificada como management outrora, reformular-se-ia como campo do saber e tecnologia administrativa diante da redemocratização e das transformações do papel (e função) do Estado.

Como campo do saber, a AP após 1980, ainda que fragmentada e, por isso, questionada, ${ }^{1}$ mesmo no estudo da organização público-estatal (e de sua burocracia), paulatinamente, apoiar-se-ia num focus político-organizacional, desatando-se do focus - puramente — administrativo. Tentava-se remover ou, no mínimo, abrandar a dicotomia política $\times$ administração, com uma interpenetração entre a ciência política e os estudos organizacionais, consoante com a repolitização (conflitos de interesses, controle social e efetividade) das repartições/agências estatais, principalmente, da administração indireta. Igualmente, com a despolarização do poder do Estado para a sociedade e a (re)estruturação das organizações sociais como stakeholders políticos, a AP - gradualmente - incorporaria as organizações públicas não estatais como objeto de estudo. Como tecnologia administrativa a AP questionaria a mera imitação (e transposição) das técnicas da administração de empresas na administração pública, seja na administração direta, seja nas empresas públicas; na análise de Cavalcanti (1984:237), a gestão pública, metaforicamente, tinha de integrar "no plano dos valores e da ação, a Atenas política à Roma administrativa, apesar das contradições, dilemas e perplexidades inerentes a tal simbiose". Substancialmente, na práxis da administração pública, a questão era como confluir a racionalização administrativa com o interesse público (e a accountability) no binômio eficiência-legitimidade, seja na formulação e implementação de políticas públicas, seja na prestação dos serviços públicos.

\footnotetext{
${ }^{1}$ Machado e colaboradores (1989), analisando 185 artigos do campo do saber de administração pública publicados nos encontros EnAnpad e na revista $R A P$, no período 1983-88, mostraram que a amplitude dos estudos e as diversas perspectivas teóricas (e instrumentos analíticos) utilizadas pelos pesquisadores ocasionavam fragmentação e não cumulação de conhecimento, sendo a AP, portanto, mais uma área de interesse do que uma disciplina no país.
} 
Essas inflexões da AP no país como área de ensino e pesquisa nos anos 1980 - que se distenderiam nos 1990 —, grosso modo, refletiam o debate (e a experiência) nos EUA sobre a educação (e profissionalização) em administração pública. Um exemplo é o livro Public administration education in transition, organizado por Thomas Vocino e Richard Heimovics em 1981, o qual publicara a indicação da Naspaa para os padrões de grade curricular e inovações no ensino de AP consoantes com: (i) a politização do processo administrativo; (ii) a incorporação - substantiva - da transparência administrativa e da justiça social no delivery do serviço público; e (iii) a orientação da burocracia para satisfazer as necessidades ou desejos dos indivíduos, quer como cidadão — interventor da realidade e portador de direitos —, quer como usuário do setor público. Semelhantemente, o documento Guidelines and standards for curricular development for public administration, editado pela International Association of Schools and Institutes of Public Administration em 1982, sugeria que o estudo da AP abordasse a gestão pública como política pública em um continuum intersetorial (e interorganizacional) entre Estado e sociedade.

Não obstante, enquanto nos EUA essas indicações/sugestões do paradigma (ou modelo de gestão) de coprodução dos serviços públicos se adequavam, imediatamente, ao ethos democrático e ao traço descentralizador do Estado norte-americano, no Brasil, a construção das instituições (e práticas) do epíteto "o público na sociedade", opondo-se à centralidade do Estado, iniciaram, de fato, após a Constituição de 1988, com a redefinição dos papéis dos níveis de governo - a qual fortaleceu o município - e a incorporação de mecanismos/ fóruns de participação de organizações (e representantes) da sociedade civil. A partir desta carta (re)democratizante é que se retomaria - indiretamente - a defesa do ensino de graduação em administração pública no país, agora, estendido às organizações públicas não estatais:

o conhecimento necessário para uma prática social coerente do administrador profissional envolve não apenas destrezas específicas, mas capacidade analítica e consciência crítica. [...] Defende-se o perfil do administrador como um agente de mudança na construção de uma sociedade mais justa e efetivamente democrática, seres criativos e questionadores antes que meros técnicos. [...]. No momento em que se vislumbra o florescimento de um pluralismo característico das sociedades democráticas, parece oportuna a formação de um profissional capaz de atuar em comunidades de base, sindicatos, partidos políticos, cooperativas, associações civis e outros campos novos à espera de formas organizativas inovadoras, além de seu tradicional campo nas empresas. (Siqueira, 1987:53) 
Este ideário "de novas formas organizativas na sociedade democrática" embasaria a Resolução no 43 da Unesp, de 30 de junho de 1988, a qual criara o curso de graduação em administração pública na Faculdade de Ciências e Letras, campus Araraquara, com o objetivo de: "Formar bacharéis capacitados a realizar intervenções em organizações voltadas para interesses coletivos, [...] podendo exercer funções diretivas em órgãos e entidades de caráter social voltadas às diversas atividades produtivas, normativas, assistenciais e cooperativas".

No entanto, a implantação de um curso de AP em tal época - inclusive de ideias-forças do Estado mínimo - colocava em dúvida (pelo senso comum) sua utilidade, como denota o testemunho de uma das professoras cofundadoras do curso da Unesp:

Propor e implantar um curso de administração pública naquele momento [1989-92] de crise do Estado não foi tarefa fácil. Nós acreditávamos no novo Estado democrático, mas a ideia de gestão pública [na acepção sociocêntrica] ainda era um pouco vaga. Em 1991 - dois anos depois de o curso ser implantado -, enquanto discutíamos a primeira reforma curricular, assistíamos ao enxugamento da máquina estatal e ao esfacelamento das instituições políticas desferidos pelo governo Collor. [...] Era complicado, em pleno Consenso de Washington você retomar a discussão do Estado, [...] a gente se passava um pouco como visionário no âmbito da universidade. Perguntas do tipo "para que serve esse curso?" eram comuns. [...] Mantivemos nossa proposta. Em meio à crise fiscal, ao processo de privatização e ao desmonte administrativo no governo Collor, procuramos focar os municípios. Achamos que era importante resgatar esse nível de governo diante do processo de descentralização em curso pós-Constituição de 1988. (entrevista realizada pelos autores, grifo nosso)

Tal bacharelado formaria sua $1^{\text {a }}$ turma em 1992, ano marcado por constantes escândalos de corrupção e impeachment - no âmbito do governo Collor -, além do descaso (e da precariedade) de alguns serviços públicos, midiaticamente veiculados para a sociedade brasileira como se fossem o retrato do conjunto da gestão pública, disseminando a ideia de que não existia competência política e capacidade administrativa no poder público. Resultado: o ceticismo em relação ao Estado oriundo dessa errônea generalização, além de dar uma conotação pejorativa para a formação acadêmica em administração pública aos olhos dos leigos, induzia os menos informados a pensarem que a AP, em questão de tempo, desapareceria como campo do saber. Como aponta Celina Souza (1998:2):

No início dos anos 1990, pessoas menos avisadas, mas muito conceituadas no mundo acadêmico da administração no Brasil, decretavam que a administração pública como disciplina estava morta. Apesar de a profecia não se ter concreti- 
zado, mostrando ser, somente, produto da desinformação e da avaliação precipitada, por outro lado ela serve de exemplo de como a disciplina era vista no país há apenas alguns anos.

Em suma, os estereótipos em torno do Estado, aprofundados pela crise do Estado, bem como a crise - paradigmática — sobre o que era administração pública, concorreram para a desvalorização social dos cursos de graduação em administração pública que subsistiram no país ao longo dos anos 1980.

\subsection{0 realento do bacharelado em administração pública no país no após 1990 em uma conjuntura de reforma do Estado, redemocratização e ampliação do locus do setor público}

Em 1993, analisando a crise, oportunidades e inovações na formação acadêmica em administração no Brasil, Tânia Fisher (1993:15-16), no que tangia ao ensino de administração pública, declarava que:

Tanto o governo quanto a sociedade manifestam desconforto e insatisfação com a estrutura organizativa e capacidade gerencial do Estado. [...] [Certamente] o administrador público está no centro do questionamento. Na década dos 1990, algumas de suas funções serão transformadas, reduzidas ou abandonadas. Mudanças de valores, tecnologias, comunicações e relações produzirão outro tipo de atividades estatais. Os gestores públicos serão (re)treinados ou recrutados por novos critérios para novas atribuições. O país requer administradores aptos a gerenciar a crise e garantir a democracia, em uma economia moderna. (grifo nosso)

Ante uma crise política (e moral) — impeachment de Collor — marcada por corrupção, desperdício e ineficiência no governo federal, e diante da agenda de reestruturação do setor público-estatal e da redemocratização, além do ambiente de instabilidade econômica (descontrole inflacionário, escassez de recursos e abertura comercial), no limiar dos anos 1990, a autora referia-se, indiretamente, às falhas institucionais e ao déficit de desempenho do modelo de administração pública brasileiro, um amálgama do ethos patrimonialista e do enrijecimento burocrático. Considera-se aqui que a redefinição do Estado — em curso - requeria um perfil de administrador público, na acepção de formação acadêmica, diferente, isto é, reformadores de Estado (governo, organizações públicas e políticas públicas) condizentes com a perspectiva do interesse público e com foco em resultados, quer no desenvolvimento socioeconômico, quer na consolidação da democracia (e melhoria do serviço público). 
Além da formação acadêmica, esse produto-educacional-meta ${ }^{2}$ de administrador para o setor público era discutido (e projetado), também, no âmbito do Estado com a (re)inserção de carreiras públicas de gestão governamental acopladas com o T\&D em escolas de governo. Na verdade, desde a criação da Escola Nacional de Administração Pública (Enap) em 1986, substituindo o Departamento Administrativo do Serviço Público (Dasp) no governo federal, e a instituição do cargo - e depois da carreira - de especialista em políticas públicas e gestão governamental (EPPGG) em 1987, a seleção e a preparação de quadros de nível superior para a União foram altercadas e tencionadas com avanços e recuos no governo José Sarney. À época, o objetivo da Enap (e da carreira de EPPGG) mostrava a noção (e intenção) do poder Executivo do Estado após 1985 de formar (e profissionalizar) uma alta burocracia — estável, moderna e competente - , descaracterizada no regime militar, como se percebe no seguinte trecho do Decreto no 93.277, de 19 de setembro de 1986: ${ }^{3}$

\begin{abstract}
o papel da escola é capacitar os profissionais que por ela passam para servir o Estado, buscando o permanente atendimento do interesse coletivo. Tratase de formar gestores que, habilitados para fazer leituras compreensivas das relações contidas no complexo Estado-sociedade, sejam capazes de participar ativamente do processo decisório no qual estiverem inseridos, interagindo com o ambiente, construindo alianças e agendando questões estratégias.
\end{abstract}

Baseada no modelo/experiência da ENA francesa, caberia à Enap a formação do estado-maior do oficialato administrativo institucionalizado pela carreira de EPPGG. Apesar da relevância/urgência deste empreendimento, no governo Collor essa escola de governo estagnou-se e tal carreira, em idas e vindas, foi extinta em 1991 e recriada em 1992. ${ }^{4}$ Irresoluto (e desamparado) na ocasião, o eixo temático da profissionalização do serviço público ressurgiria no biênio 1993/94, no mandato de Itamar Franco, em uma tentativa de recuperar a autoestima da administração pública federal e reaver a política de recursos humanos no governo.

Ainda em meados de 1992, sob o patrocínio do Ministério do Trabalho e da Enap, realizou-se um encontro entre as instituições de formação e pesquisa

\footnotetext{
${ }^{2}$ Utilizando-se da expressão de Kliksberg (1983).

${ }^{3}$ Sobre as origens da Enap e a concepção da carreira de especialistas em políticas públicas e gestão governamental, ver Castro, Pinheiro e Machado (1994).

${ }^{4}$ Sobre esses percalços, ver a dissertação de mestrado de Carmem Maria (2000).
} 
em administração aplicada ao setor público (IESs e escolas de governo), reunindo 26 técnicos/acadêmicos para refletir sobre a capacitação/aperfeiçoamento de pessoal como estratégia de reforma do Estado. Dos anais deste meeting, lê-se:

Consideramos um grande avanço a adoção, pelo governo federal, de um discurso centrado na questão da capacitação dos recursos humanos. Diferentemente das posições assumidas quando da posse do presidente, em 1990, observa-se hoje a passagem de um enfoque quantitativo (enxugamento, demissões, disponibilidade) para um mais qualitativo, repondo aspectos mais substantivos no âmbito da reforma administrativa a esse respeito. [...] [Certamente], a concentração de esforços no aperfeiçoamento de pessoal pode ser o peão de um movimento favorável à criação de uma nova cultura administrativa e política no país, generalizando uma nova tábua de valores abertos à cidadania, à democracia, à responsabilidade pública e à eficiência". (Enap, 1992:8; grifo nosso)

Conforme o gap de cultura administrativa na burocracia - práticas clientelistas, disfunções burocráticas e deficiências de competências - e lacunas nesta tábua de valores no aparelho do Estado comprometiam a gestão governamental e as políticas públicas em um ambiente de elevada escassez de recursos econômico-financeiros e natural competição (e constrangimento) político-eleitoral, urgir-se-ia tanto o sistema de mérito no serviço público como o T\&D do servidor público para a profissionalização da administração pública no país. Na União, a partir de 1995, no bojo do Plano Diretor da Reforma do Aparelho do Estado no governo FHC, esses imperativos seriam acatados com a retomada das carreiras públicas e a intensificação dos programas de educação continuada, sobretudo, na Enap.

Tal como na União, os estados que conduziam reformas administrativas retomariam os concursos públicos e os cursos de atualização/reciclagem para o funcionalismo público. Em Minas Gerais, por exemplo, o fato de o poder Executivo, através da escola de governo da Fundação João Pinheiro (FJP), implantar um curso de graduação em administração pública vinculado ao ingresso na carreira de administrador público estadual era uma entre diversas iniciativas de profissionalização do serviço público que ocorreriam em unidades da federação. Entretanto, esta experiência mineira, na qual o vestibular é um concurso público e o curso de formação é um bacharelado, era - e ainda é - atípica (e surpreendente). Comumente, os governos estaduais criariam a carreira de gestão pública — provida por profissionais de nível superior aprovados em concurso público que, inicialmente, eram submetidos a T\&D intensivo -, semelhante à carreira de EGGPP com formação na Enap no governo 
federal. Mato Grosso, Bahia, Goiás e Pernambuco são alguns dos estados que adotariam este modelo no final dos anos 1990.

De fato, esta centralidade (ou atenção) na profissionalização dos gestores públicos despontava na agenda de reforma do Estado nacional (e subnacional) à medida que a administração pública renovava seus modelos de gestão, preconizando transformar as estruturas burocráticas rígidas/estanques em arranjos organizacionais flexíveis/inovadores. A adoção (e alcance) de uma gestão pública - de fato - profissional requeria a estruturação de carreiras, a valorização dos concursos públicos, a promoção pelo sistema de mérito, a avaliação de desempenho e a capacitação permanente, desde os altos cargos de direção/assessoramento até a street level bureaucracy (Levy, 1997).

$E^{\prime}$ a partir desta agenda de reforma do Estado que o front de ensino em administração pública se revitalizaria no Brasil; no âmbito governamental, o T\&D coordenado e/ou ministrado por escolas de governo e institutos de administração pública cresceria nos três níveis de governo com programas, temas e conteúdos para a (re)qualificação do servidor público; no âmbito acadêmico, o ensino superior em administração pública valorizar-se-ia na pós-graduação, aumentando as pesquisas nos programas de mestrado (ou áreas de concentração) stricto sensu de AP (Ebap, Eaesp, UFBA, FJP) e correlatos, e vicejando cursos de especializações lato sensu em gestão pública (e políticas públicas) abertos nas IESs e in the job nos órgãos públicos.

Ademais, a retomada da profissionalização no serviço público com a (re)ativação de carreiras públicas, o aumento da governança (e das políticas públicas) no nível subnacional com o binômio descentralização-redemocratização e a emergência do terceiro setor reabririam o mercado de trabalho para o bacharel em administração pública. Nesta conjuntura de reforma do Estado e ampliação do locus do setor público no país, o ensino de graduação em administração pública realentaria após 1990 em comparação com a letargia dos anos 1980. Em 1994, a Eaesp reestruturava a grade curricular do bacharelado em ADM, consoante com a modificação do currículo mínimo de administração de 1993; na habilitação de AP, a opção pelo perfil generalista e a flexibilidade das disciplinas eletivas, supostamente, adequavam o curso à diversidade de oportunidades/possibilidades profissionais no Estado, no terceiro setor e, mesmo, na iniciativa privada. Neste ano, também, a FJP iniciava seu ensino de graduação em administração pública voltado, exclusivamente, para a formação acadêmica de estudantes que, recebendo um salário mínimo - mensalmente - nos quatro anos de curso, após o término, ascenderiam à carreira de administradores públicos no governo de Minas Gerais. Posteriormente, em 1995, a graduação em administração pública da Unesp, orientada — aparentemente — para a administração municipal, era, então, reconhecida 
pelo Ministério da Educação. Assim, desde meados dos anos 1990, os cursos de AP dessas IESs, cada qual com sua especificidade, tornar-se-iam as referências do ensino de graduação em administração pública no Brasil.

Algo que favorecia, em termos, os cursos de graduação em administração pública era a alteração do currículo mínimo de administração pelo Conselho Federal de Educação depois de 27 anos. Ainda que a rigidez de disciplinas obrigatórias (e cargas horárias) continuasse e a concepção de administração como AE permanecesse, as IESs tinham, agora, a flexibilidade de compor 960 horasaula, ou seja, $32 \%$ do curso. No caso dos bacharelados em AP, neste espaço de disciplinas eletivas (e complementares) poder-se-iam incluir e/ou ampliar os estudos típicos/exclusivos do setor público de acordo com as especificidades do curso. Outrossim, mediante a intensificação de estudos de um conjunto de matérias afins, os cursos, além da habilitação geral prescrita em lei (no caso, $\mathrm{AE}$ e AP), se desejassem, poderiam - agora — ter habilitações específicas; políticas públicas, gestão municipal e terceiro setor, por exemplo, eram algumas de muitas habilitações específicas exequíveis em um curso de graduação em AP. A Resolução do CFE no 2, de 4 de outubro de 1993, que estipula tais modificações no ensino de graduação em administração, encontra-se no quadro 3.

Ressalta-se que, por um erro de interpretação desta resolução por parte das autoridades educacionais (CFE, MEC, Angrad e CFA), as quais olvidaram do Parecer no 307, de 8 de julho de 1966, que previa as opções (e denominações) de administração de empresas e administração pública para os cursos de graduação em administração, o desígnio de AP tornou-se uma habilitação específica quando, historicamente, era uma habilitação geral. Resultado: a nomenclatura - facultada por lei — de curso de graduação em administração pública, neste processo, equivocadamente, foi descredenciada. Curso de graduação em administração, habilitação em administração pública, constituía, então, a denominação que os bacharelados em AP, obrigatoriamente, adotariam..$^{5} \mathrm{Em}$ 1995, enquanto as IESs se adequavam a tal resolução, o cadastro da SESu/MEC

\footnotetext{
${ }^{5}$ Após a Resolução no 4/2005 do Conselho Nacional de Educação, a qual instituiu as Diretrizes Curriculares Nacionais (DCNs) para o curso de graduação em administração, tal erro foi notado (e admitido); com a extinção das habilitações específicas — revogando a Resolução no 2/1993 do Conselho Federal de Educação - , as autoridades educacionais definiram a "existência, exclusivamente, das denominações de 'Curso de Administração' e de 'Curso de Administração Pública', esta última fundamentada na própria origem dos cursos de administração no Brasil, e, ainda, acompanhando o entendimento do Parecer CFE $n^{\circ}$ 307, de 8 de julho de 1966" (Angrad/ CFA, 2005:1, grifo nosso). Atualmente (2010), discute-se no âmbito do Conselho Nacional de Educação a proposição de Diretrizes Curriculares Nacionais (DCNs) para os cursos de graduação em administração pública, incluindo os cursos de gestão pública, gestão de políticas públicas, políticas públicas e gestão social.
} 
registrava 354 cursos de graduação em administração no país, sendo $13 \mathrm{com}$ habilitação em administração pública, com destaque para os da Eaesp, Unesp e Fundação João Pinheiro, apresentados — brevemente — no quadro 4.

\section{Currículo mínimo do curso de graduação em administração em 1993}

Art. 1 - O currículo mínimo do curso de graduação em administração, que habilita ao exercício da profissão de administrador, será constituído das seguintes matérias:

Formação básica e instrumental

$\checkmark$ economia

$\checkmark$ direito

v matemática

- estatística

- contabilidade

vilosofia

v psicologia

- sociologia

v informática

Total: 720 horas-aula

Formação profissional

v teorias da administração

v administração mercadológica

v administração da produção

v administração de recursos humanos

v administração financeira e orçamentária

v administração de materiais e patrimoniais

v administração de sistemas de informação

v organização, sistemas e métodos

Total: 1.020 horas-aula

\section{Disciplinas eletivas e complementares}

Total: 960 horas-aula

Estágio supervisionado

Total: 300 horas-aula
Art. 2 - O curso de administração será ministrado no tempo útil de 3.000 horas-aula, fixando-se para sua integralização o mínimo de quatro e o máximo de sete anos letivos. [...].

Art. 3o - Além da habilitação geral prescrita em lei, as instituições poderão criar habilitações específicas, mediante a intensificação de estudos correspondentes às matérias fixadas nesta resolução e em outras que venham a ser indicadas para serem trabalhadas no currículo pleno.

Parágrafo único - A habilitação geral constará do anverso do diploma e as habilitações específicas, não mais de duas de cada vez, serão designadas no verso, podendo assim o diplomado completar estudos para obtenção de novas habilitações.

Art. 4ํ- os mínimos de conteúdos e duração fixados nesta Resolução serão obrigatórios a partir de 1995, podendo, as instituiç̃̃es que tenham condições para tanto e assim desejarem, aplicá-los a partir de 1994.

Art. 5o - Na obtenção de graduação em administração, por diplomados em outros cursos, caberá às escolas o estabelecimento de critérios flexíveis de aproveitamento de estudos obtidos pelo aluno em seu curso anterior, especialmente quanto aos programas de estudos e respectiva dosagem, obedecidas as normas legais.

Parágrafo Único - A graduação obtida nos termos deste artigo deverá ser ministrada no tempo útil de 1.350 horas-aula.

Artigo 6- - A presente Resolução entra em vigor na data de sua publicação, revogadas as disposições em contrário.

Fonte: MEC, Resolução do CFE no 2, de 4 de outubro de 1993 (grifos nossos). 


\section{Quadro 4 \\ Tríade do ensino de graduação em administração pública no Brasil nos anos 1990}

\begin{tabular}{|c|c|}
\hline IES & Descrição \\
\hline Eaesp/FGV & $\begin{array}{l}\text { O curso de graduação em administração - habilitação em AP - da Eaesp/FGV foi } \\
\text { criado em } 1969 \text { no âmbito de um convênio estabelecido entre esta IES e o governo do } \\
\text { estado de São Paulo (Gesp). Financiado por recursos públicos estaduais - e, portanto, } \\
\text { gratuito aos alunos -, o curso propunha-se nos tempos idos a "preparar pessoas para } \\
\text { ocupar cargos de níveis médio e alto na máquina administrativa paulista". Em 1996, o } \\
\text { fim do convênio entre a Eaesp e o Gesp tornou o curso de AP pago. Desde então, "as } \\
\text { ameaças de extinção, a baixa atração de alunos com vocação e a pouca diferenciação } \\
\text { dos programas de ensino de AP e AE nessa IES", descaracterizaram - parcialmente - a } \\
\text { habilitação (na atualidade, linha de formação específica) em administração pública. }\end{array}$ \\
\hline FCL/Unesp & $\begin{array}{l}\text { O curso de bacharelado em administração com habilitação em AP da Unesp, campus } \\
\text { Araraquara, foi concebido no triênio 1986-88 por professores - na ocasião - dos } \\
\text { Departamentos de Economia e de Antropologia Política da Faculdade de Ciências e } \\
\text { Letras (FCL) dessa universidade. Implantado em 1989, o curso objetivava em seu } \\
\text { estágio inicial "formar um profissional de gestão pública especialmente qualificado } \\
\text { para o trato de questões municipais em um ambiente de redemocratização". Após a } \\
\text { formatura de sua primeira turma (1992), iniciou-se a organização do Departamento } \\
\text { de Administração Pública que, dois anos mais tarde, levou a cabo uma reestruturação } \\
\text { curricular, acatando a Resolução no } 2 \text { do CFE de } 1993 \text { - Currículo Mínimo de } \\
\text { Administração. Enfim, em 1995, o curso fora reconhecido pelas autoridades } \\
\text { educacionais. }\end{array}$ \\
\hline EG/FJP & $\begin{array}{l}\text { O curso de bacharelado em administração com habilitação em AP da Escola de } \\
\text { Governo da FJP foi instituído em } 1994 \text { com o propósito de "constituir-se em } \\
\text { instrumento estratégico para a modernização do serviço público mineiro". Trata-se de } \\
\text { um curso superior único (e inovador) no país, orientado para a formação acadêmica } \\
\text { de profissionais que integrarão, depois de graduados, uma carreira de Estado, a de } \\
\text { especialista em políticas públicas e gestão governamental (EPPGG) do governo do } \\
\text { estado de Minas Gerais. Além disso, o ensino é gratuito e os alunos que não são } \\
\text { servidores públicos recebem, mensalmente, uma bolsa de estudo correspondente a um } \\
\text { salário mínimo. }\end{array}$ \\
\hline
\end{tabular}

Fonte: elaboração dos autores, baseado em análise documental e entrevistas.

Finalizando, assim como o processo de redemocratização no país e o anseio de profissionalização da burocracia (mineira) inspiraram, respectivamente, a criação dos cursos de graduação em administração pública na Unesp em 1989 e na FJP em 1994, após 1995 e, sobretudo, a partir dos anos 2000, percebe-se que o aprofundamento da reforma do Estado nos três níveis de governo, além do crescimento do setor público não estatal, geraram — e pros- 
seguem gerando - ânimos para o ensino de graduação em administração pública no Brasil, com o (re)surgimento de bacharelados em AP e correlatos (gestão pública, gestão de políticas públicas, políticas públicas e gestão social) em IESs públicas federais e estaduais.

\section{Considerações finais}

Este artigo constrói um retrospecto descritivo-analítico de um dos ciclos do ensino de graduação em administração pública no Brasil, referente ao período 1983-94. Diferente do $1^{\circ}$ ciclo (1952-65) e do $2^{\circ}$ ciclo (1966-82), quando a formação acadêmica de tais cursos tinha uma identidade - aderente à concepção (e projeto) de Estado e aos contornos (e produção) do campo do saber da administração pública - , tendo na Ebap/FGV um case modelar, demonstramos que o 3 o ciclo foi um estágio de construção "problemático", refletindo a crise do Estado dos anos 1980 e, igualmente, a crise (ou descontinuidade) paradigmática do campo do saber em administração pública no Brasil em tal época. Neste ínterim, a extinção do bacharelado em AP da Ebap/FGV (1983) demarcou a letargia de tal ensino, enquanto a continuidade do curso de graduação em AP - nos anos 1980 - na Eaesp/FGV e a implantação desta formação acadêmica na Unesp (1989) e na FJP (1994) representaram um realento, em um contexto de reforma do Estado e redemocratização. Enfim, para o intervalo de tempo (1983-94) analisado, cabe a conclusão - anterior — de Fischer (1984:12), referente ao período 1930-79, de que "o ensino de administração pública no Brasil não é produto do acaso, mas — historicamente - um produto da conjuntura do Estado nacional".

Pode-se afirmar que Eaesp/FGV, Unesp e EG/FJP são as IESs que mantiveram vivo o ensino de graduação em administração pública no país, contribuindo com sua subsistência, bem como referenciando o (re)surgimento de bacharelados em AP e correlatos a partir do final dos anos 1990 e início dos anos 2000. Em linhas gerais, apesar de alguns obstáculos (identidade difusa, escassez de material didático e carência de corpo docente em algumas áreas - constatados por Coelho, 2006), tornaram-se cursos tradicionais (e os mais conhecidos) e indicados como os melhores nos rankings do MEC e "guias de estudantes".

Ademais, considerados como embasamento histórico, os relatos/constatações deste artigo são, per se, um constructo para se refletir, retrospectivamente, sobre o ensino de graduação em administração pública no país. Indubitavelmente, qualquer investigação (e compreensão) desse objeto de estudo 
no presente, sem suas referências do passado, tende a resultar em um trabalho (e compreensão) falho e/ou incompleto. Cita-se, por exemplo, a importância de tais referências/memória neste momento — biênio 2010/11 — em que se discutiu e aprovaram no Conselho Nacional de Educação (CNE) as diretrizes curriculares nacionais para os cursos de graduação em administração pública e afins. Sem dúvida, em tal discussão, as experiências/lições do passado são fundamentais.

\section{Referências}

CASTRO, M.H.; PINHEIRO, M.L; MACHADO, E. Profissionalização dos quadros superiores da administração pública. Revista do Serviço Público, ago./set. 1994.

CAVALCANTI, B. Formação do administrador público: alternativas em debates. Revista de Administração Pública, jul./set. 1981.

CAVALCANTI, B. A gestão pública como componente do desenvolvimento curricular das escolas de administração. Revista de Administração Pública, out./dez. 1984.

CAVALCANTI, B. A gestão pública integrada: implicações para a formulação de teorias, modernização administrativa e ensino de administração pública. Revista de Administração Pública, jul./set. 1991.

COELHO, F.S. Educação superior, formação de administradores e setor público: um estudo sobre o ensino de administração pública - em nível de graduação — no Brasil. Tese (doutorado) — Escola de Administração de Empresas de São Paulo, Fundação Getulio Vargas, São Paulo, 2006.

COELHO, F.S. Radiografia do ensino de graduação em administração pública no Brasil (1995-2006). In: ENANPAD, 2008. Anais... Rio de Janeiro, 2008a.

COELHO, F.S. Revisitando as origens do ensino de graduação em administração pública no Brasil (1854-1952). In: ENAPG, 2008. Anais... Salvador, 2008b.

COSTA, J. Fundação Getulio Vargas: pioneirismo a serviço do desenvolvimento nacional. Rio de Janeiro: FGV, 1984.

COVRE, M.L. A formação e a ideologia do administrador de empresas. São Paulo: Cortez, 1991.

CUNHA, A. Educação em administração pública: retrospectiva e perspectivas da experiência norte-americana e reflexões sobre o caso brasileiro. Revista de Administração Pública, jul./set. 1981. 
DURHAM, E. Educação superior, pública e privada (1808-2000). In: BROCK, C.; SCHWARTZMAN, S. (Org.). Os desafios da educação no Brasil. Rio de Janeiro: Nova Fronteira, 2005.

ENAP. Relatório do Encontro de Instituições de Formação e Pesquisa em Administração Pública. Brasília: Escola Nacional de Administração Pública, 1992. Mimeografado.

FLEURY, P. O ensino de graduação em administração no Brasil: um estudo de casos. Revista de Administração de Empresas, out./dez. 1983.

FISCHER. T. O ensino de administração pública no Brasil: os ideais de desenvolvimento e as dimensões de racionalidade (1948-1984). Tese (doutorado) — Faculdade de Economia e Administração, Universidade de São Paulo, São Paulo, 1984.

FISCHER. T. A formação do administrador brasileiro na década de 90: crise, oportunidade e inovações nas propostas de ensino. Revista de Administração Pública, out./dez. 1993.

INTERNATIONAL Association of Schools and Institutes of Public Administration. Guidelines and standards for curricular development for public administration/public management. 1982. Mimeografado.

KLIKSBERG, B. Universidad, formación de administradores y sector público en América Latina. México: Clad, Inap, Fondo de Cultura Económica, 1983.

LEVY, E. Formação e capacitação na construção de um novo Estado. Texto para Discussão, Brasília, n. 19, 1997.

MACHADO DA SILVA, C.; AMBONI, N.; CUNHA, V. Produção científica em administração pública: período 1983-1988. In: ENANPAD, 1989. Belo Horizonte: Anpad, 1989.

MACHADO, M. O ensino de administração pública no Brasil. Rio de Janeiro: FGV, 1966.

MARIA, C. Meritocracia a brasileira: a trajetória da carreira dos gestores governamentais. Dissertação (mestrado) — Escola de Administração de Empresas de São Paulo, Fundação Getulio Vargas, São Paulo, 2000.

MARTINS, C. Le nouvel enseignement supérier au Brésil. Tese (doutorado) - Universidade de Paris, Paris, 1986.

MARTINS, C. Surgimento e expansão dos cursos de administração no Brasil (19521983). Revista da Sociedade Brasileira para o Progresso da Ciência, jul. 1989.

MEC. Parecer nº 307 e Resolução s/n do Conselho Federal de Educação, de 8 de julho de 1966 - fixa o currículo mínimo do curso de administração no Brasil. 
MEC. Resolução do Conselho Federal de Educação no 2, de 4 de outubro de 1993 — institui o currículo pleno dos cursos de graduação em administração e dá outras providências.

MEZZOMO KEINERT, T. Os paradigmas da administração pública no Brasil (190092). Revista de Administração de Empresas, maio/jun. 1994.

MEZZOMO KEINERT, T. Análise das propostas dos cursos de administração pública no Brasil em função da evolução do campo de conhecimento. São Paulo: NPP, série relatório de pesquisa, Eaesp/FGV, 1996.

MEZZOMO KEINERT, T. Do aparelho estatal ao interesse público: crise e mudança de paradigma na produção técnico-científica em administração pública no Brasil (1937-1997). Tese (doutorado) — Escola de Administração de Empresas de São Paulo, Fundação Getulio Vargas, São Paulo, 1998.

MOURA CASTRO, C. A profissionalização do administrador e o amadorismo dos cursos. Revista de Administração de Empresas, mar./abr. 1974.

NICOLINI, A. Aprender a governar: aprendizagem formal e informal no contexto das carreiras de governo. Tese (doutorado) — Escola de Administração, Universidade Federal da Bahia. Salvador, mimeo, 2007.

PACHECO, R. Administração pública nas revistas especializadas - Brasil, 19952002. Revista de Administração de Empresas, out./dez. 2003.

PRESTES MOTTA, F. A questão da formação do administrador. Revista de Administração de Empresas, Rio de Janeiro, out./dez. 1983.

SILVA, B. Gênesis do ensino de administração pública no Brasil. Cadernos de Administração Pública, n. 49, 1960.

SIQUEIRA, M. O papel das disciplinas de embasamento na formação acadêmica de administradores. Revista de Administração de Empresas, Rio de Janeiro, v. 27, n. 1, p. 53-54, jan./mar. 1987.

SOUZA, C. Pesquisa em administração pública no Brasil: uma agenda para o debate. Revista de Administração Pública, jul./ago. 1998.

VOCINO, T.; HEIMOVICS, R. (Org.). Public administration education in transition. New York: Marcel Dekker, 1982. 